\title{
Skin Metastasis with Non-healing Ulcer: An Unusual Presentation of Metastasis of Carcinoma Cervix
}

\author{
N SAYEEDA $^{\mathrm{a}}$, S RAHMAN $^{\mathrm{b}}$, S NAHAR $^{\mathrm{c}}$, A SULTANA $^{\mathrm{d}}$
}

\begin{abstract}
Summary:
Carcinoma of the uterine cervix is the most common gynecological malignancy in developing countries. Most frequent metastasis of carcinoma cervix occurred locally. Distal metastasis via lungs, bones, liver reported frequently but skin metastasis are very rare incidence. Here we present a case of skin metastasis of carcinoma cervix.
\end{abstract}

A 42 year old lady presented with a skin swelling with non-healing ulcer over the swelling in outpatient

\section{Introduction:}

Carcinoma of the uterine cervix is the most common gynecological malignancy in developing countries. 15 to $61 \%$ women with cervical cancer will develop distant metastases within the first two years of completing treatment. ${ }^{1}$ The most frequently seen metastases sites are lungs, bone and liver $^{2-4}$. Skin metastases are unusual event in the late stages of disease with a quoted incidence ranging from $0.1 \%$ to $4.4 \% .{ }^{5-10}$ Mostly these metastases occur as a first sign of recurrence and are associated with poor prognosis.

We report an unusual case of cutaneous metastasis in a 42-years-old woman that preceded the diagnosis of cervical carcinoma.

\section{Case Report:}

A 42 years old woman, housewife of lower socioeconomic condition presents with the complaints of swelling on the left side of lower abdomen and formation of ulcer with discharge over the swelling

a. Dr. Nur Sayeeda, Professor of Gynae. \& Obstetrics Department, Dhaka Medical College, Dhaka.

b. Dr. Shamima Rahman, Junior Consultant, Gynae. \& Obstetrics Department, Dhaka Medical College, Dhaka.

c. Dr. Shamsun Nahar, Junior Consultant (Gynae), Upazilla Health Complex, Debhatta, Satkhira.

d. Dr. Sultana Afroj, Associate Professor of Gynae. \& Obstetrics Department, Dhaka Medical College, Dhaka.

Address of correspondence: Dr. Nur Sayeeda, Professor of Gynae. \& Obstetrics Department, Dhaka Medical College, Dhaka, Phone-01911343259,Email: n.sayeeda 03@gmail.com

Received: 3 December, 2017

Accepted: 6 September, 2018 department of Dhaka Medical College. She had history of Wertheim's Hysterectomy 1year back for carcinoma cervix stage II A (FIGO classification). On skin biopsy she was diagnosed as a case of cutaneous metastasis of carcinoma cervix.

Key word: Carcinoma cervix, Skin metastasis

(J Bangladesh Coll Phys Surg 2019; 37: 89-92)

DOI: https://doi.org/10.3329/jbcps.v37i2.40567

for 6 months. She had treated for ulcer by antibiotic. Dressing was done by local doctor. But her condition was not improved. Previously she had a history of Wertheim's hysterectomy on 17.01.2016 for Carcinoma Cervix stage II A according FIGO classification 1 year back. And underwent operation one year back. Histo-pathological examination of operated specimen revealed well differentiated adenocarcinoma of cervix without any lymph node involvement. Her postoperative period was uneventful. Then she was referred to Radiotherapy Department for adjuvant therapy but she did not receive radiotherapy and did not return for follow up. She had anorexia and weight loss but no history of fever, cough, chest pain and haemoptysis. Her bowel habit was normal.

On examination she was moderately anaemic, anorexic, non-icteric. There was a swelling and ulcer over the lower part of abdomen along the previous surgical scar involving supra-pubic and left hypo-gastric areas,

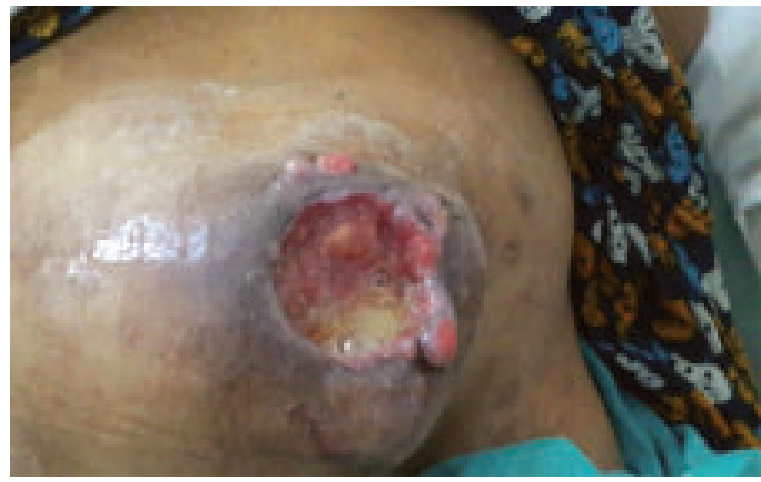

Fig.-1: Swelling over lower abdomen 


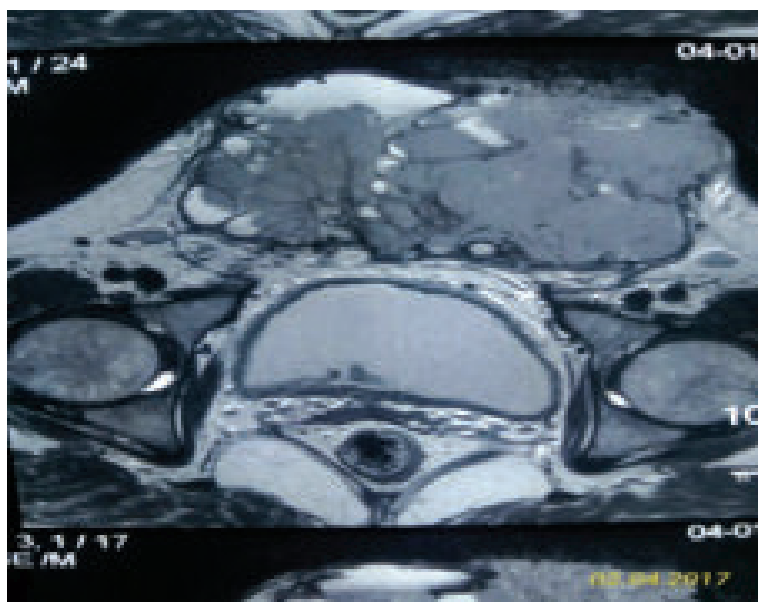

Fig.-2: MRI of lower abdomen

measuring about $11 \mathrm{~cm} \times 8 \mathrm{~cm}$, hard in consistency, tender, fixed with underlying structure, margin ill defined, overlying skin was ulcerated.The ulcer was irregular in shape, everted edge, floor was covered with necrotic tissue.Base was fixed and indurated. Surrounding skin was hyperemic having slough and foul smelling sero-sanguinous discharge on the base. There was no inguinal lymphadenopathy.

On per vaginal examination vault looked apparently healthy without any discharge or bleeding. On bimanual examination hard nodules was felt above the right side of the vault. Biopsy from the ulcer revealed metastatic adenocarcinoma. Ultrasonography of whole abdomen reported that there was an irregular hypo echoic solid mass $(11.4 \times 7.3) \mathrm{cm}$ just beneath the left half of the scar tissue in the lower abdomen. Doppler study showed that the lesion was highly vascular and densely adherent with the overlying skin.

Trans-vaginal USG revealed that uterus was absent. There was a small irregular hypo echoic soft tissue structure $(3.4 \times 2.3) \mathrm{cm}$ posterior to urinary bladder which could not be separated from the vault. MRI finding showed recurrence of carcinoma in vault $(6.5 \times 3.2) \mathrm{cm}$. There was a metastasis $(13.5 \times 8 \times 8.5) \mathrm{cm}$ in lower anterior abdominal wall occupying more on left para-median wall. Anteriorly it invaded the muscles, subcutaneous fat and skin of anterior abdominal wall and anterior wall of urinary bladder posteriorly. There was no bony involvement and no pelvic lymphadenopathy or ascites.

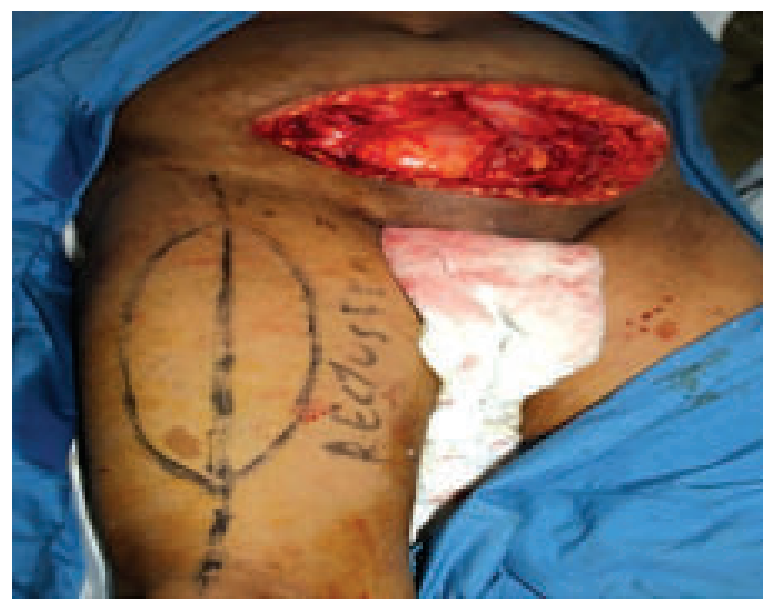

Fig.-3: Surgical treatment

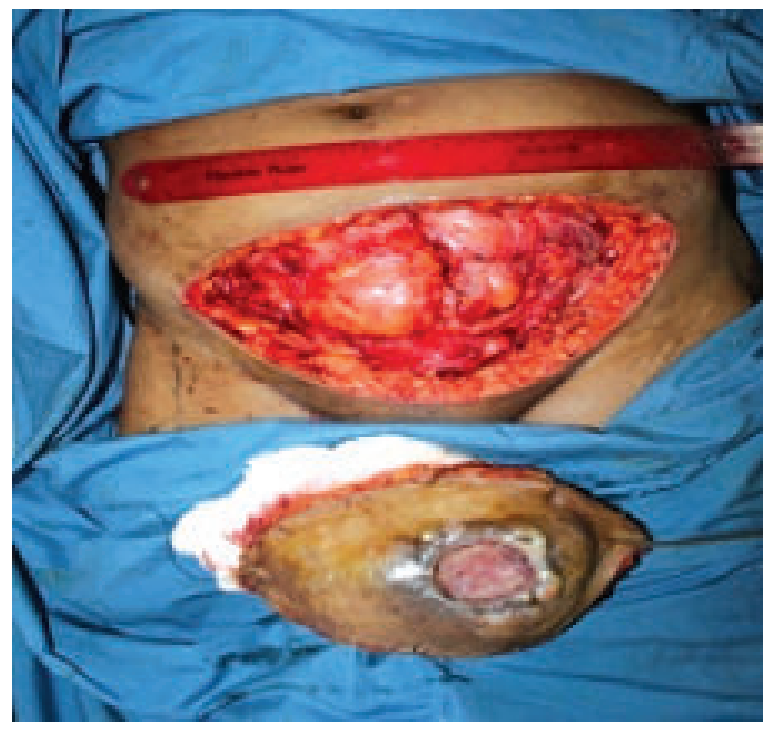

Fig.-4: Surgical treatment

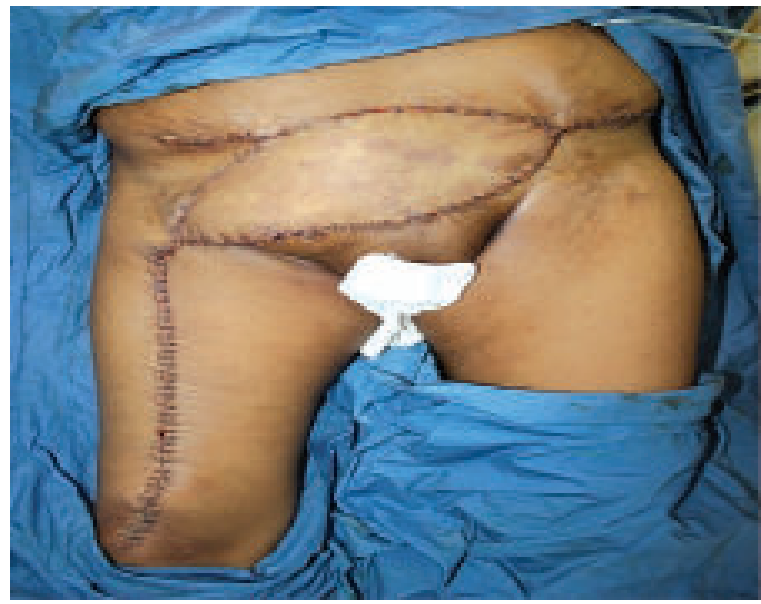

Fig.5: After rectas femoris flap coverage 
For patient management a medical board was formed by Department of Obstetrics and Gynaecology, Plastic Surgery and Oncology. The board decided for: a. surgical excision of the tumour \& rectus femoris flap coverage followed by chemo and radiotherapy. For this purpose patient was referred to Plastic Surgery Department. Excision of the lesion and reconstruction of the defect with rectus femoris flap.

Histopathology report of tissue from anterior abdominal wall revealed metastatic adenocarcinoma with metastasis in right inguinal lymph node). Metastatic Adenocarcinoma. The deep resection margin was free of the tumor Patient received chemotherapy for 6 cycle. Her general condition was good and she had no major complication.

\section{Discussion}

The Cervical Cancer endanger the lives of the women in most of the cases due to lack of consciousness in the developing countries. The spread of carcinoma cervix mainly by direct extension but lymph node metastasis is also common to paracervical, hypogastric, obturator and external iliac group. Skin metastasis are extremely rare event with incidence range from $>01$ to $2 \% 5$. Skin metastases has poor prognosis as it is usually associated with local or regional recurrence. We report a case of patient who presented with skin metastasis in anterior abdominal wall around previous scar area one year following one year of Wertheim's Hysterectomy. Skin metastasis is rare and only occur in case of advanced carcinoma cervix. It may be due to inadequate surgical excision and follow up. Our patient was not at advanced stage so she underwent surgical excision (Wertheim's hysterectomy). So it was evident that skin metastasis may be due to inadequate surgery or implantation of cancer cell during primary surgery. Patient also did not come for further follow up and treatment.

Treatment of distal metastasis nearly always palliative and consist of radiation, chemotherapy and surgery either alone or in combination. ${ }^{5.6}$ Similarly we also did surgical excision of whole tumour with rectus femoris flap coverage in collaboration with department of plastic surgery followed by chemotherapy. The prognosis of skin or distal metastasis is poor. The mean survival is usually 3 month. Survival for more than 1 year was found in only $20 \%$ of patient. $5,7,, 8$ Our case is good health passed one and half year without any major complication. Now she is under regular follow up.

Imachi $\mathrm{M}^{10}$ et al in 1993 studied 1190 patients with carcinoma of the uterine cervix.

Among them 15 (1.3\%) developed skin metastases. The incidence of skin metastasis was $0.8 \%$ in stage I, $1.2 \%$ in stage II, $1.2 \%$ in stage III, and $4.8 \%$ in stage IV. The incidence of skin metastasis seemed to be higher in patients with adenocarcinoma and undifferentiated carcinoma than in patients with squamous cell carcinoma ${ }^{11}$. Our reported case had also adenocarcinoma. The interval between the diagnoses of cervical cancer and skin metastasis ranged from 0 to 69 months, with a mean of 16.9 months. ${ }^{10}$

Bellefqih $\mathrm{S}^{11}$ et al in 2003 reported an unusual case of cutaneous metastasis in a 37-years-old woman that case was later diagnosed as a case of carcinoma of the uterine cervix without any other metastasis. She was treated with the excision of the cutaneous metastasis followed by three cycles of chemotherapy. She was treated with pelvic irradiation. The patient died three months after. ${ }^{11}$

\section{Conclusion:}

Cutaneous metastases is a uncommon occurrence in case of carcinoma cervix.Physicians should be aware that skin manifestations may be the first sign of metastasis in carcinoma of the uterine cervix. Awareness of such infrequent patterns of metastases in cervical cancer is important for best therapeutic decisions. To prevent this unwanted course of disease we should be more careful about spillage and implantation of tissue during surgical procedure specially malignant cases. We should also counsel the patient to complete the treatment and follow up properly in malignant lesions.

\section{Referances}

1. Shanta V, Krishnamurthi S, Gajalakshmi CK, Swaminathan R, Ravichandran K. Epidemiology of cancer of the cervix: global and national perspective. J Indian Med Assoc.2000;98: 49-52.

2. Carlson V, Delclos L, Fletcher GH. Distant metastases in squamous-cell carcinoma of the uterine cervix. Radiology. 1967; 88:961-966. 
3. Berek JS, Hacker NF. Practical gynecologic oncology. Philadelphia: Lippincott Williams \& Wilkins. 2000 :360-380.

4. Disaia PH, Creasman WT. Clinical gynecology-oncology. (5thedn), St. Louis: Mosby.1997; 85-90.

5. Brady LW, O'Neill EA, Farber SH . Unusual sites of metastases.Semin Oncol.1977;4; 59-64.

6. Brownstein MH, Helwig EB. Metastatic tumors of the skin. Cancer.1972; 1298-1307.

7. Lookingbill DP, Spangler N, Helm KF. Cutaneous metastases in patients with metastatic carcinoma: a retrospective study of 4020 patients. JAm Acad Dermatol.1993; 29: 228-236.
8. Lookingbill DP, Spangler N, Sexton F. Skin involvement as the presenting sign of internal carcinoma. A retrospective study of 7316 cancer patients. J Am Acad Dermatol.1990; 22: 19-26.

9. Malfetano JH. Skin metastases from cervical cancer: a fatal event. Gynecol Oncol.1986;24: 177-182.

10. Imachi M, Tsukamoto N, Kinoshita S, Nakano H. Skin metastasis from carcinoma of the uterine cervix. GynecolOncol .1993; 48: 349-354.

11. Sara Bellefqih1, Imane Mezouri1, Jihane Khalil1, Adama Diakité1, Khannoussi BE2, TayebKebdani1, Brahim El Gueddari1, Noureddine Benjaafar. Skin Metastasis of Cervical Cancer:About an Unusual Case. J Clin Case Rep 2013; 3 